\title{
Detection of Fetal Heart Movement in First Trimester of Pregnancy using Pulsed Ultrasound
}

\author{
HUGH P. ROBINSON
}

British Medical fournal, 1972, 4, 466-468

\section{Summary}

A method is reported by which the presence or absence of fetal heart movement may be reliably detected by an abdominal approach from the 48th day of pregnancy onwards (menstrual age). The technique involves the use of commercially available diagnostic sonar apparatus using two display and time position modes in combination.

A series of 106 examinations on 56 patients in early pregnancy is presented in which there were no false results.

\section{Introduction}

Until the introduction of ultrasound the assessment of an early pregnancy, especially in cases of threatened abortion, proved a difficult problem as clinical examination and immunological urine testing in such cases is often unhelpful and may even be misleading. With the advent of sonar, however, Donald (1967, 1969) showed that it is possible to follow the increase in size of the gestation sac from as early as the fifth week of pregnancy,* though a reliable estimation of growth rate required at least two examinations separated by a period of one week (Donald $e t$ al., 1972). On the other hand, the use of those instruments which use the ultrasonic Doppler principle can provide an immediate answer to the question of fetal life by detecting fetal heart movement. This technique is now a well established procedure (Johnson et al., 1965; Bernstine and Callagan, 1966; Bishop, 1966; Pystynen et al., 1968; Barton, 1968; Brown et al., 1968; Kuah and Embrey, 1968; Muller and Osler, 1969; Resch et al., 1971) but when an abdominal transducer is used it is unreliable before the 12th week of pregnancy. By using a vaginal transducer, however, Jouppila (1971) was able to detect fetal heart action by the Doppler technique at the eighth week of pregnancy, and reported $100 \%$ accuracy from the 10th week.

With unidimensional or A scan sonar equipment, and with the transducer probe directed through the maternal abdomen, Pystynen et al. (1968) were able to display fetal heart movement reliably only from the 14th week, while Bang and Holm (1968) with a combination of A and time position (T.P.) modes in a small series of patients were unable to record heart movement until the 12th week of pregnancy. Kratochwil and Eisenhut (1967), on the other hand, when using a vaginal transducer and A scan instrumentation, detected fetal life from the seventh week and achieved reliable results from the 10th week.

It appears, therefore, that a vaginal transducer with either Doppler or A scan equipment might provide the best method of detecting the presence of fetal heart movement. This technique, however, has the obvious disadvantage of a prolonged vaginal examination which may prove unacceptable to the patient, especially when bleeding and threatening to abort. With either method an immediate assessment as to the presence of fetal life

* All references to gestation in this report refer to menstrual age.

cannot be accurately given until after the 10th week of pregnancy, and as a large proportion of threatened abortions present before this period of gestation a reliable method of detecting fetal life in the earlier weeks is required. This report describes such a method, the technique used involving the use of an abdominal instead of a vaginal approach.

\section{Method}

The apparatus used was the new Nuclear Enterprises Diasonograph NE4102, which has the facility of displaying simultaneously any two of the three display modes (A, B, and T.P.). This arrangement greatly accelerates and simplifies the procedure. The "full bladder technique" described by Donald (1963) is routinely used, though in a thin patient is not always necessary. A $2.5 \mathrm{MHz}$ transducer is used with a pulse repetition of 300 pulses per second.

The patient's abdomen is liberally smeared with warm olive oil to provide good acoustic coupling, and, using the B mode, the uterus is quickly scanned to locate and display the gestation sac. The fetus is then located, and electronic markers are placed along the beam in position above and below the fetal echoes (Fig. 1). The transducer is now held in such a position that the

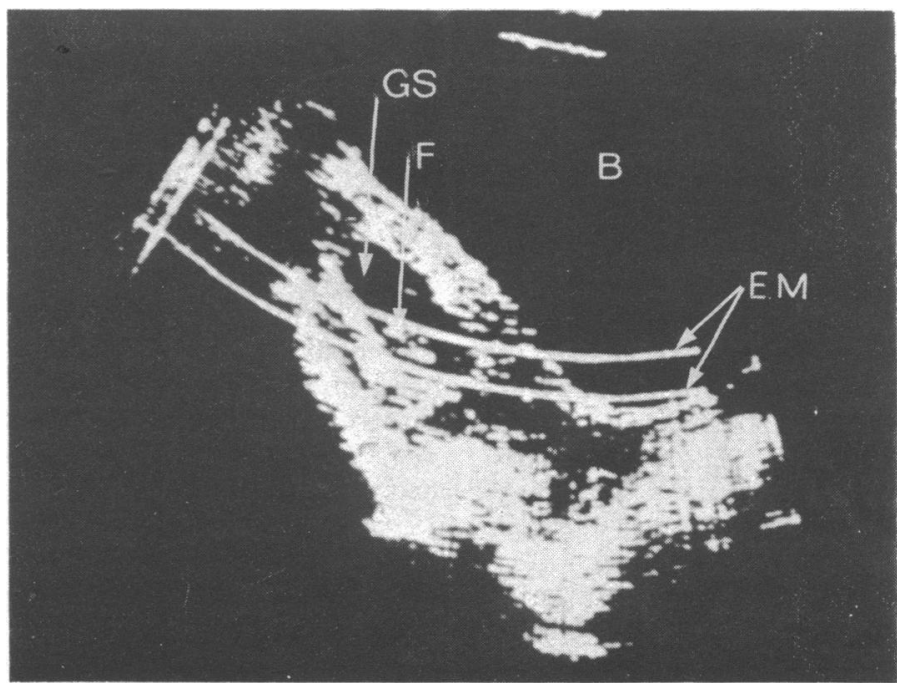

FIG. 1-An eight-week pregnancy with electronic markers (E.M.) placed above and below the fetal echoes. (Scale $2: 5$.) $B=$ Bladder. $G S=$ Gestation sac. $\mathrm{F}=$ Fetus.

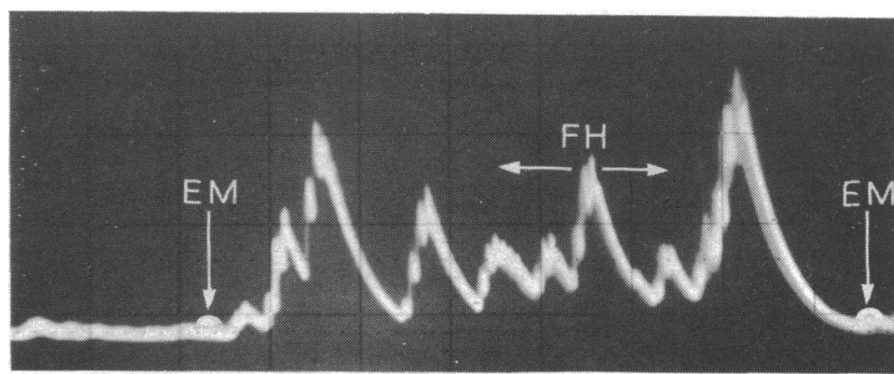

FIG. 2-An A scan display in which the echoes from $2 \mathrm{~cm}$ of tissue have been expanded to $10 \mathrm{~cm}$. All the echoes between markers $(\mathrm{EM})$ originate from fetus. Echoes from fetal heart structures (FH) move synchronously with its pulse in directions indicated by arrows. 
ultrasonic beam traverses the fetus. Attention is next directed to the simultaneous A scan display on the adjacent cathode ray screen on which the electronic markers are depicted as bright dots (Fig. 2). The echoes between these markers thus originate from fetal structures. The transducer is now moved fractionally until echoes are seen which are rapidly undergoing positional and amplitude changes at a frequency which depends on the fetal heart rate. The original B scan display is then converted by a press-button switch to the T.P. mode in which the echo movement patterns are converted to linear traces. Those echoes which originate from a moving structure are recorded as a regular waveform, while stationary structures are represented as straight lines. These tracings are photographed from a storage cathode ray oscilloscope for record purposes (Fig. 3). Since the time of the sweep period is known the heart rate is easily calculated, and is usually found to be over 160 beats per minute in the first trimester of pregnancy.

With practice the maximum time taken to locate the fetus and to record the heart movements is less than five minutes, and, in most cases, less than two minutes.

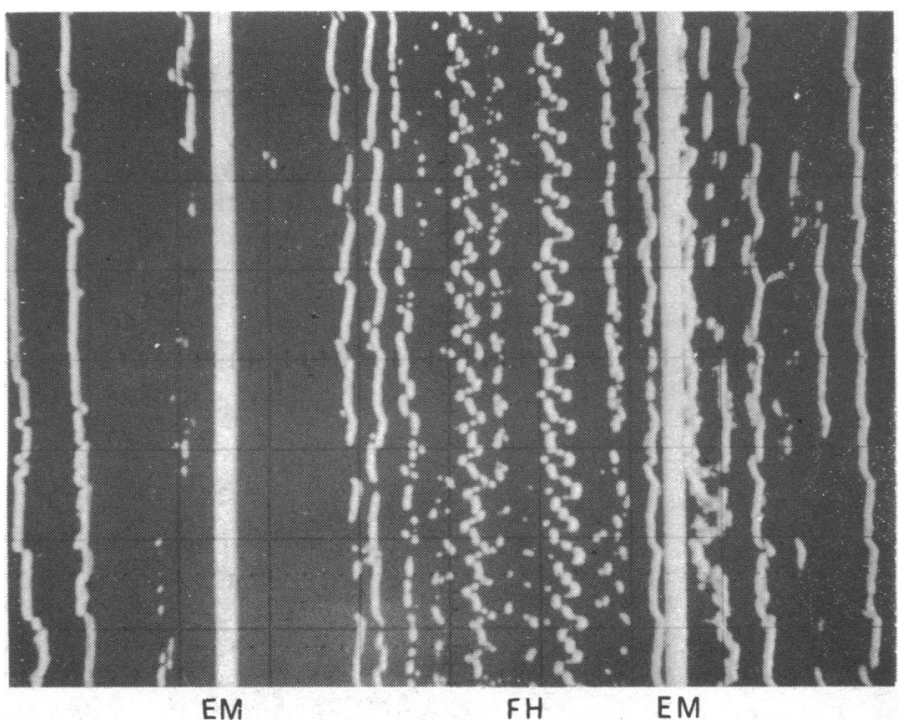

FIG. 3-Time position scan in same scale as Fig 2. Two regular waveforms (FH) between markers (EM) are derived from fetal heart structures. Sweep period is 7.5 seconds and calculated heart rate is 165 beats per minute.

\section{Results}

Fifty-six patients requiring an opinion as to pregnancy viability were examined to determine the presence of fetal heart movement. All were certain of their menstrual dates and all were before 15 weeks' gestation. A total of 106 examinations were performed.

Twenty-three of the patients were examined on more than one occasion at weekly intervals, the maximum being five. The indications for the initial investigation are shown in Table $I$, and

TABLE 1-Indication for Sonar Examination in 56 Patients

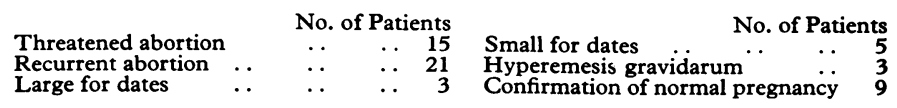

the total number of positive and negative examinations and the accuracy rate at each gestational age is shown in Fig. 4.

Fetal ezhoes and fetal heart movements were positively identified and recorded in all 42 patients with over 47 days' amenorrhoea who, at the time of writing, had continuing pregnancies. There were no false-negative results.

The sonar findings of the remaining 14 patients, all of whom subsequently aborted, are shown in Table II.

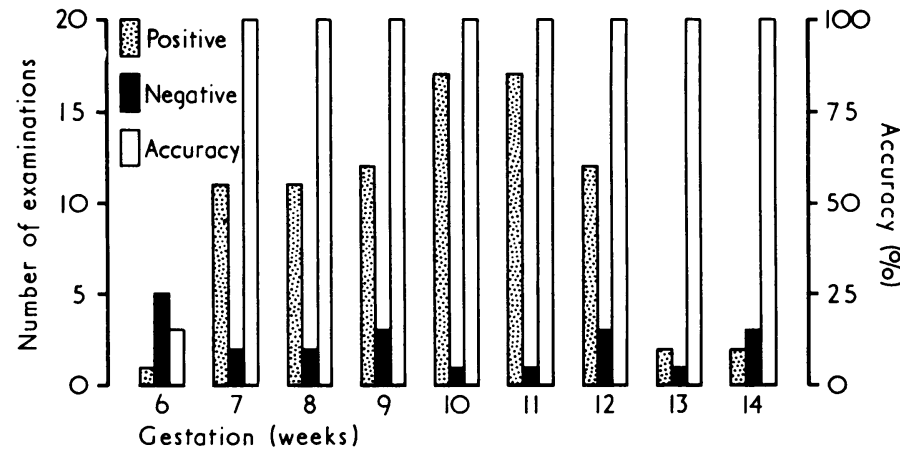

FIG. 4-Analysis of results of investigations.

TABLE II-Sonar Findings of 14 Patients who Subsequently Aborted

\begin{tabular}{llrrrr} 
Fetus identified and fetal heart movements detected & $\ldots$ & & \multicolumn{3}{c}{ No. of Patients } \\
Fetus identified but fetal heart movements not present & $\ldots$ & $\ldots$ & $\ldots$ & 3 \\
Blighted ovum-no fetal echoes or heart movements identifiable & $\ldots$ & $\ldots$ & 4 \\
Missed abortion- disorganized gestation sac, no fetal heart movements present & 1
\end{tabular}

Two of the three patients in whom a fetus was identified and fetal heart movement was detected aborted four weeks after the examination, and in each case the length of the abortus was consistent with the period of amenorrhoea. It was, therefore, assumed that in both cases the fetus was alive at the time of the sonar scan. The third patient aborted a fresh fetus on the day after the examination, the length of which was compatible with the stage of pregnancy. For this reason this case was also not thought to be a false-positive finding.

All four patients in whom definite fetal echoes were seen but no heart movement was detected aborted within two days of the examination. In each case a macerated fetus was identified.

A diagnosis by sonar of "blighted ovum" was made in six cases, and was based on the already recognized signs described by Donald et al. (1972). In none of these cases could a fetal heart beat be detected. Of the six patients, two aborted empty intact sacs, two aborted broken sacs in which there was no evidence of fetal tissue, and the remaining two aborted necrotic trophoblast only.

The sonar findings in the final case were those of disorganized tissue with no evidence of a gestation sac or of a fetus. The uterus was evacuated on the next day and necrotic decidua and trophoblast was obtained.

\section{Discussion}

Diagnosis of the presence or absence of fetal heart movements was reliably established in this series from the 48th day of amenorrhoea. Essential factors for successful examination are a readily controllable high grade sensitivity of the equipment, and the facility of being able to determine and positively direct the sonar beam on to the fetus. By this means it is possible to concentrate attention on the echoes arising from fetal structures, and to distinguish from them maternal pulsations.

Since, in this series, there were no false-positive or falsenegative findings the clinical value of this technique has much to offer, such as the reassurance that the fetus in a case of threatened abortion is still in fact alive. On the other hand a suspected diagnosis of missed abortion can be readily confirmed and distinguished from those patients with continuing pregnancies but in whom the size of the uterus does not correspond clinically to the stated menstrual dates. Before undertaking operations such as cervical cerclage (Shirodkar type) it is now our practice to confirm the viability of the pregnancy by identifying movement of the fetal heart.

When this technique is used as a means of serial monitoring in patients with threatened or recurrent abortion the practice of routine urine pregnancy testing may be superfluous, and at times misleading. It is further suggested that with increasing 
use many of the problems of early pregnancy and their management may be expeditiously resolved.

I would like to thank Professor Ian Donald for his advice and encouragement, and the members of staff of the Queen Mother's Hospital, Glasgow, for referring the patients included in this study.

This work has been undertaken with financial help from the Medical Research Council granted to Professor Ian Donald as programme director of a current long-term research schedule in the University of Glasgow.

\section{References}

Bang, J., and Holm, H. H. (1968).American fournal of Obstetrics and Gynecology, 102,956.

Barton, J. J. (1968). American Fournal of Obstetrics and Gynecology, 102, 563.
Bernstine, R. L., and Callagan, D. A. (1966). American fournal of Obstetrics and Gynecology, 95, 1001 .

Bishop, E. H. (1966). American Fournal of Obstetrics and Gynecology, 96, 863 Brown, A. D. G., and Robertson, J. G. (1968). Fournal of Obstetrics and Gynaecology of the British Commonwealth, 75, 92 .

Gynaecology of the British Commonwealth, 75, 92.
Donald, I. (1963). British Medical fournal, 2, 1154.

Donald, I. (1967). British fournal of Radiology, 40, 604.

Donald, I. (1969). Fournal of Pediatrics, 75, 326.

Donald, I., Morley, P., and Barnett, E. (1972). Fournal of Obstetrics and Gynaecology of the British Commonwealth, 79, 304

Johnson, W. L., Stegall, H. F., Lein, J. N., and Rushmer, R. F. (1965). Obstetrics and Gynecology, 26, 305.

Jouppila, P. (1971). Acta Obstetricia et Gynecologica Scandinavica, 50, 1. 15.

Kratochwil, A., and Eisenhut, L. (1967). Gerburtshilfe Frauenheilkd, 27, 176 Kuller K., and Embrey, M. P. (1968). British Medical fournal, 1, 438. navica, 48, Suppl, M. (1969). Acta

navica, 48, Suppl. No. 3, p. 130. Gynaecologicae Fenniae, 57, 607.

Resch, B., Herczeg, J., Altmayer, P., and Sztano, P. (1971). Annales Chirurgiae et Gynaecologiae Fenniae, 60, 85.

\section{PRELIMINARY COMMUNICATIONS}

\section{Treatment of Acute Myeloblastic Leukaemia with RP 22050}

\author{
C. JACQUILLAT, M. WEIL, M. F. GEMON, \\ V. IZRAEL, G. SCHAISON, M. BOIRON, \\ JEAN BERNARD
}

British Medical fournal, 1972, 4, 468-469

\section{Summary}

Fourty-four patients with acute myeloblastic leukaemia were treated with RP 22050, a new, semisynthetic derivative of daunorubicin. Complete remissions were achieved in 20 patients $(45 \%)$. The median dose given was $23 \mathrm{mg} / \mathrm{kg}$. The toxicity of RP 22050 is mainly haematological. Resistance rather than death in aplasia seemed to be the cause of failure of therapy.

\section{Introduction}

The therapeutic index of the benzol hydrazone chlorhydrate of daunorubicin, RP 22050 (see fig.), in the treatment of acute leukaemia is better than that of daunorubicin and its toxicity less than that of daunorubicin and of adriamycin (Skeel et al., 1970). We report here a trial of RP 22050 in 44 patients with acute myeloid leukaemia.

\section{Patients and Methods}

Fifteen of the 44 patients were children and 29 were adults. Their age and sex distribution is shown in table I. Twenty-five were in their first attack of the disease, and of these 20 had had no previous treatment. The remaining 19 patients were suffering a relapse, and they and five of the patients in their first attack

\footnotetext{
Department of Haematology, Institut de Recherches sur les Leucémies, Hôpital Saint-Louis, Université de Paris, France C. JACQUILLAT, M.D., Professor M. WEIL, M.D., Departmental Head M. F. GEMON, M.D., Assistant V. IZRAEL, M.D., Assistant G. SCHAISON, M.D., Professor M. BOIRON, M.D., Professor J. BERNARD, M.D., Professor
}

had been previously treated either with daunorubicin alone (two patients) or with daunorubicin in combination with cyclophosphamide, cytosine arabinoside, and L-asparaginase (protocol 09-71). All five patients in their first attack of the disease who had had previous treatment were resistant to these drugs.

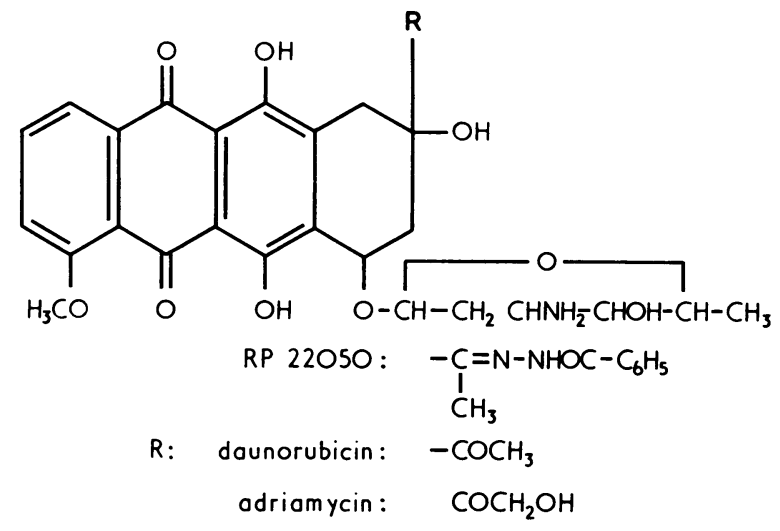

Structure of RP 22050, daunorubicin, and adriamycin.

TABLE I-Distribution of Cases of Acute Myeloid Leukaemia Treated by $R P 22050$

\begin{tabular}{|c|c|c|c|c|c|}
\hline & \multicolumn{2}{|c|}{ First Attack } & \multirow[b]{2}{*}{ 1st Relapse } & \multirow[b]{2}{*}{ 2nd Relapse } & \multirow[b]{2}{*}{ Total } \\
\hline & $\begin{array}{l}\text { No Previous } \\
\text { Treatment }\end{array}$ & $\begin{array}{c}\text { Previous } \\
\text { Treatment }\end{array}$ & & & \\
\hline $\begin{array}{l}\text { Children } \\
\text { Adults }\end{array}$ & $\begin{array}{r}5 \\
15\end{array}$ & $\begin{array}{l}2 \\
3\end{array}$ & $\begin{array}{r}6 \\
10\end{array}$ & $\begin{array}{l}2 \\
1\end{array}$ & $\begin{array}{l}15 \\
29\end{array}$ \\
\hline Total & 20 & 5 & 16 & 3 & 44 \\
\hline
\end{tabular}

RP 22050 was given by intravenous infusion in saline in a daily dose of $3-5 \mathrm{mg} / \mathrm{kg}$ until the total dose reached $20 \mathrm{mg} / \mathrm{kg}$. Blood counts were made daily and bone marrow counts on the fifth, 10th, 15th, 20th, and 25th days. Aplasia of the bone marrow was usually noted after the 10th day, and if blast cells then persisted, even though white cells might be $1,000 / \mathrm{mm}^{3}$ or fewer, additional doses of RP $220503 \mathrm{mg} / \mathrm{kg}$ were given. One additional dose was given when blast cells were between $10 \%$ and $20 \%$, two doses when they were between $20 \%$ and $50 \%$, and three doses when they were more than $50 \%$. Antibiotic treatment was essential during the aplastic phase in all patients. All patients also had platelet transfusions and 17 had transfusions of white cells from donors with chronic myeloid leukaemia. 